\title{
The Freezing Point of Uranium
}

\section{By Andrew I. Dahl and Harold E. Cleaves}

\begin{abstract}
The freezing temperature of uranium of about 99.99-percent purity was measured with an optical pyrometer and found to be $1,133^{\circ} \pm 2^{\circ} \mathrm{C}$. Both the initial purity and the initial freezing temperature were lower than the foregoing values. However, holding the metal at temperatures just above the melting point for several hours resulted in a decrease in the content of several impurities and an increase in the freezing temperature to a final constant value.

The freezing temperature was not greatly affected by the crucible material, similar values being obtained in beryllia, thoria, and graphite crucibles.
\end{abstract}

\section{Introduction}

Concurrent with the great increase of interest in the metal, uranium, brought about by the role of this metal in the field of atomic energy, there has been an initiation of investigations to obtain more accurate values of certain physical properties of the element. Previously, the metal was of little practical importance and was not available in a state of sufficient purity to give a positive significance to the results of determinations of many of its physical properties. Only a few of the physical constants of uranium were listed in tables published before 1943, and those listed were highly discordant. As a result of the atomic energy program conducted by the Manhattan District, Corps of Engineers, United States A:my, there became available a quantity of uranium of relatively high purity. This paper describes the work on the freezing point of uranium done at the National Bureau of Standards for the Manhattan Project.

\section{Previous Work}

A survey of various tables and handbooks published before 1943 shows the freezing point of uranium is listed as $<1,850^{\circ} \mathrm{C}[1],{ }^{1} 1,860^{\circ} \mathrm{C}$ [2], $2,400^{\circ} \mathrm{C}$ [3], and $3,600^{\circ} \mathrm{C}$ (computed on the basis of the position formerly assigned to uranium in the periodic system) [4]. Information regarding: the method of arriving at the values quoted is

\footnotetext{
${ }^{1}$ Figures in brackets indicate the literature references at the end of this paper.
}

generally lacking. J. W. Mellor [5] cited values of $1,300^{\circ}$ to $1,400^{\circ} \mathrm{C}, 1,600^{\circ}$ and $1,850^{\circ} \mathrm{C}$ and made the statement "uranium melts less easily than platinum, chromium, and molybdenum but more easily than tungsten and vanadium". Driggs and Lilliendahl [6] reported observed values of $1,688^{\circ}$ and $1,690^{\circ} \mathrm{C}$. Fisher and Rideal [7] reported $1,300^{\circ}$ to $1,400^{\circ} \mathrm{C}$. In $1941 \mathrm{~W}$. F. Roeser [8] observed $1,075^{\circ}$ and $1,100^{\circ} \mathrm{C}$ for two samples of impure uranium melted in vacuum.

The large spread in values reported for the melting point of uranium probably may be explained by the fact that a casing or crust is formed on the surface of uranium when it is heated in the presence of certain gases. This casing encloses the molten metal until temperatures far above the melting point of uranium are reached. For example, in some experiments at this Bureau, a specimen of uranium did not melt down when heated to about $1,800^{\circ} \mathrm{C}$ in a furnace evacuated to about $3 \mathrm{~mm}$ of mercury, whereas other specimens cut from the same ingot melted below $1,200^{\circ}$ $\mathrm{C}$ when heated in a furnace evacuated to a few microns pressure. The flat surfaces of the first specimen became convex during heating, which indicates that the casing was sufficiently plastic to distort at the higher temperatures reached but, nevertheless, it was not ruptured by the head pressure of the molten metal. Obviously, the melting point of uranium may be much lower than the temperature at which the molten metal breaks through the casing. 
The melting or freezing of a pure or nearly pure metal is accompanied by the absorption or evolution of its latent heat of fusion. During the change of state the temperature remains essentially constant. Thus, the heating or cooling curves of the metal will indicate the true melting or freezing point.

\section{Present Work}

\section{Materials}

Three samples of uranium designated as $A_{1}, A_{2}$, and $B$ were used in the present work. Samples $A_{1}$ and $A_{2}$ were cut from the same extruded rod, sample $B$ was cut from a cast ingot. The initial purity of samples $A_{1}$ and $A_{2}$ was about 99.94 percent, that of sample $B$ was about 99.96 percent. Carbon and iron were the major impurities.

\section{Experimental Procedure}

The so-called crucible method was followed in the freezing-point determinations. In this method a hollow enclosure, or black body, is immersed in a bath of the metal, and observations on the radiation from the black body are made with an optical pyrometer during the time the metal is freezing. The uranium was melted in a highfrequency induction furnace. This type of heating provides stirring and consequently a high degree of temperature uniformity throughout the molten sample and minimizes the probability of contamination of the sample by the furnace elements.

Each of the uranium samples was melted in a different refractory - sample $A_{1}$ in beryllia, sample $A_{2}$ in graphite, and sample $B$ in thoria. All of the crucibles were identical in size and shape. The beryllia and thoria crucibles were prepared by the general method described by Swanger and Caldwell [9]. The graphite crucible and accessory parts were made by machining. In each case the sight tube and the powdered material at the bottom of the tube were made of the same material as the crucible.

The uranium ingots, about $380 \mathrm{~g}$ in weight, were formed to the desired shape by hot forging. An axial hole was drilled in each ingot to accommodate the sight tube. Each sample was placed in its crucible and mounted in a larger porcelain container, as shown in figure 1 . In the case of the samples contained in the beryllia and the graphite crucibles, lampblack was used as thermal insulation. The crucible assembly containing sample $A_{2}$ was heated in an Arsem furnace evacuated to about $2 \mathrm{~mm}$ for $16 \mathrm{hr}$ at about $1,000^{\circ} \mathrm{C}$ to eliminate volatile products from the carbon insulation. Thoria powder was used as insulation for the sample in the thoria crucible. The assembly shown in figure 1 was placed inside a Pyrex glass

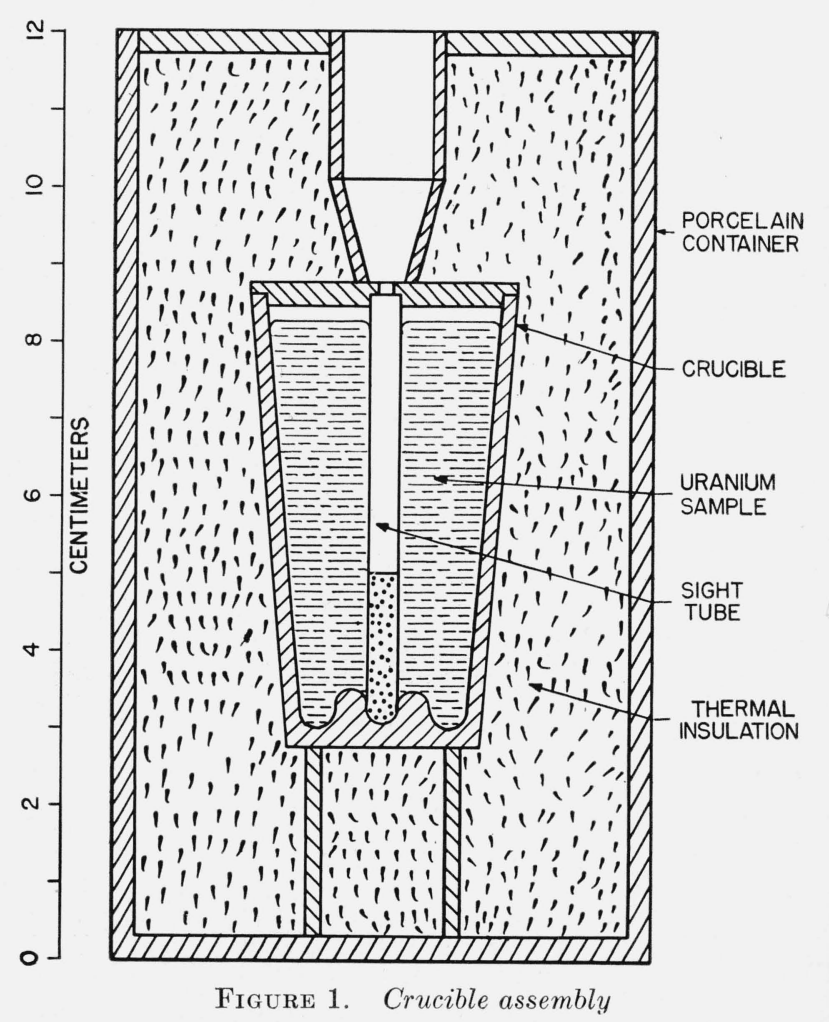

enclosure, shown in figure 2. The tube was closed at the top with a pyrex window sealed to the tube with propylene phthalate. The Pyrex tube fitted closely inside the water-cooled coils of the induction furnace.

Since uranium oxidizes rapidly even at moderate temperatures, the metal must be melted either in an inert atmosphere or in vacuum. Previously, melting uranium in vacuum had been found to produce an evolution of volatile material that deposited on the window and interfered with temperature measurements with an optical pyrometer. Use of an inert gas at atmospheric pressure would be expected to minimize this interference. Purified helium was selected as the protective atmosphere in the present work.

The optical pyrometer used has been previously described by Fairchild and Hoover [10]. It was 
fitted with a 45-deg totally reflecting prism for sighting vertically into the black body. The current-temperature relation of the pyrometer lamp was obtained by a calibration method based on the definition of the International Temperature Scale. ${ }^{2}$ The identical prism and window employed in the freezing-point determinations were used in the calibration.

The Pyrex enclosure was flushed out with helium for about $2 \mathrm{hr}$ before heating of the sample was started, and a helium atmosphere was maintained during the actual heating. A freezing-point observation consisted in heating the metal to a temperature about $50 \mathrm{deg} \mathrm{C}$ above its melting point and then allowing the sample to cool slowly. Observations were made during the time the metal was freezing, as indicated by the halt in the cooling process. The average number of pyrometer readings obtained during one freeze was seven. The uranium samples exhibited no undercooling prior to solidification.

\section{Results}

The initial freeze on uranium sample $A_{1}$ indicated a freezing temperature of $1124.9^{\circ} \mathrm{C}$. Subsequent freezes indicated a progressive rise in the freezing temperature, the fifth freeze indicating a freezing point of $1126.8^{\circ} \mathrm{C}$. Following the fifth freeze the sample was melted and maintained at a temperature about $50 \mathrm{deg} \mathrm{C}$ above the melting point for a period of $30 \mathrm{~min}$. The next two freezes indicated a freezing temperature of $1128.0^{\circ} \mathrm{C}$. Thereafter the sample was held in the molten state for periods of 1 to $5 \mathrm{hr}$ between sets of freezingpoint observations until the heating period totaled $22 \mathrm{hr}$. A constant freezing-point limiting value

${ }^{2}$ In this method, the lamp current corresponding to the gold point $\left(1,063^{\circ} \mathrm{C}\right)$ is determined by matching the brightness of a portion of the lamp filament with that of a black body in freezing gold. The apparatus used is similar to that shown in figure 1 , but an inert atmosphere is not required. The calibration is extended to higher temperatures by using a black body furnace and rotating sector disks of known transmission [11]. The temperature of the furnace is adjusted until its brightness, when viewed through a given rotating sector disk, is equal to that of the black body at the gold point. The temperature of the black body furnace, $T^{\circ} \mathrm{K}$, may be calculated with sufficient accuracy using the following formula derived from Wien's law

$$
\ln t=\frac{1.438}{\lambda_{e}}\left(\frac{1}{T}-\frac{1}{T_{A u}}\right),
$$

where $t$ is the fractional transmission of the sector disk; $\lambda_{e}$ is the effective wavelength of the optical pyrometer in centimeters; and $T_{\mathrm{A} u}$ is the absolute temperature of the gold point. The sector disk is then removed and the current increased to obtain a brightness match between pyrometer lamp and black body furnace. This current corresponds to the temperature, T. By utilizing sector disks having different angular openings, the lamp current for various temperatures higher than the gold point may be determined and a complete calibration obtained by interpolation. of $1131.5^{\circ} \mathrm{C}$ for the freezing point was observed after about $15 \mathrm{hr}$ of heating. In reckoning the total heating period, each set of freezing-point observations was regarded as the equivalent of 6 min of heating in the molten state. The change

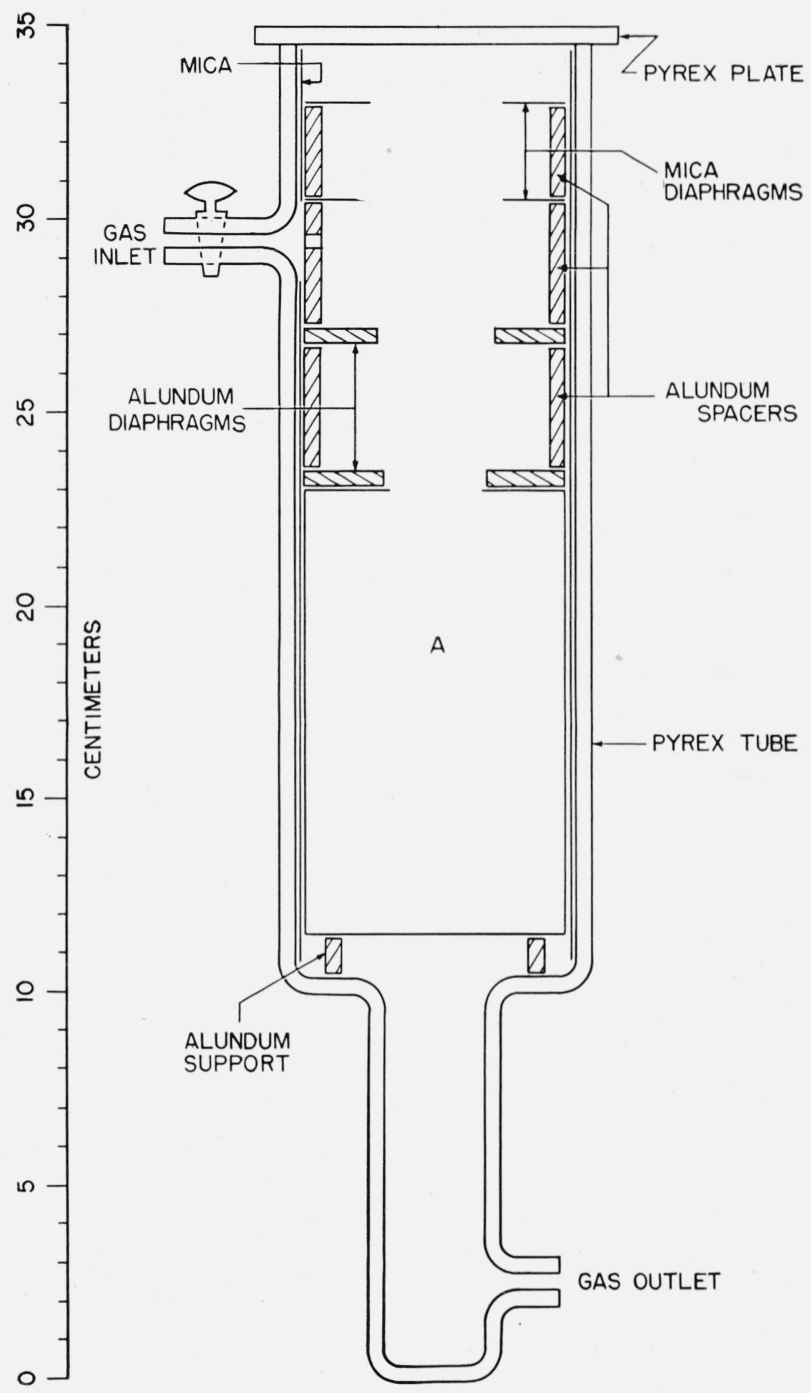

Figure 2. Crucible asoembly in Pyrex envelope

A, Porcelain container with sample as shown in figure 1.

in the freezing temperature of uranium sample $A_{1}$ with time of heating is shown graphically in figure 3 .

Observations of the freezing points of uranium samples $A_{2}$ and $B$ also indicated a progressive rise in the freezing temperature with increase in the time the material was held in the molten state. A summary of the freezing-point observations on the three samples of uranium is given in table 1 . 


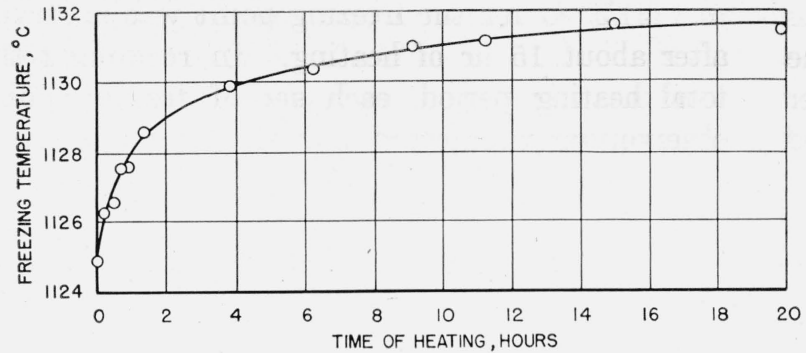

Figure 3. Freezing temperature versus time of heating for uranium sample $A_{1}$.

TABLE 1. Summary of freezing-point observations

\begin{tabular}{|c|c|c|c|}
\hline \multirow{2}{*}{$\begin{array}{l}\text { Time held in } \\
\text { molten state }\end{array}$} & \multicolumn{3}{|c|}{ Freezing Temperature } \\
\hline & $\begin{array}{c}\text { Sample } \\
A_{1}(\text { in } \mathrm{BeO})\end{array}$ & $\begin{array}{c}\text { Sample } \\
A_{2} \text { (in graphite) }\end{array}$ & $\begin{array}{c}\text { Sample } \\
B(\text { in ThO })\end{array}$ \\
\hline$h r$ & ${ }^{\circ} \mathrm{C}$ & ${ }^{\circ} \mathrm{C}$ & ${ }^{\circ} \mathrm{C}$ \\
\hline 0 & 1125. & 1128. & 1128. \\
\hline $3 / 2$ & 1127. & -.......... & 1128.5 \\
\hline 1 & 1128. & - & 1129. \\
\hline 2 & 1129. & 1129.5 & 1130. \\
\hline 5 & 1130. & 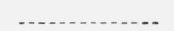 & 1131.5 \\
\hline 7 & - & 1131. & -...... \\
\hline 10 & 1131. & - & 1133. \\
\hline 15 & 1131.5 & 1131.5 & 1133.5 \\
\hline 20 & 1131.5 & - & 1133.5 \\
\hline
\end{tabular}

Each of the temperature values in the above table for heating periods of $5 \mathrm{hr}$ or greater is the mean of the value of three to five successive freezes. The uncertainty in the temperature values, resulting from uncertainties in photometric matching and lamp calibration, is believed to be within \pm 2 deg $\mathrm{C}$.

The factors that cause inaccuracies in meltingand freezing-point determinations tend to produce low values; hence the highest value obtained in the three determinations, rounded to $1,133^{\circ} \pm 2^{\circ} \mathrm{C}$ is believed to best represent the freezing point of uranium.

\section{Discussion of Results}

Uranium samples $A_{1}$ and $A_{2}$, from the same source, exhibited a difference in freezing temperature during the initial portion of the heating period but attained the same final value of $1,131.5^{\circ} \mathrm{C}$ after a 15-hr heating period. This initial difference may have resulted from the preliminary heating for $16 \mathrm{hr}$ in vaccuum, given sample $A_{2}$ but not $A_{1}$. The higher initial purity of sample $B$ may account for its initial freezing point being higher than that of sample $A_{1}$.
Analysis of the ingots after the freezing temperature determinations showed a substantial increase in the purity of the metal, to about 99.99 percent for samples $A_{1}$ and $B$ and slightly less for sample $A_{2}$. The content of some impurities, including oxygen, remained about the same. Iron was increased about $15 \mathrm{ppm}$. Some impurities, notably carbon and nitrogen, were decreased in amount, some were completely eliminated.

The outstanding decrease was in the carbon content, which was reduced from about 400 to 5 ppm in ingot $A_{1}$ and from 150 to $7 \mathrm{ppm}$ in ingot $B$. The melting and freezing procedure resulted in a reduction of the carbon content of ingot $A_{2}$ from about 400 to $110 \mathrm{ppm}$ for a sample representing the full cross section of the ingot, even though a graphite crucible was used.

Metallographic examination of the ingots after the melting-point determination gave a qualitative confirmation of these low carbon contents and indicated the mechanism by which the carbon was eliminated from the body of the ingot. Ingots $A_{1}$ and $B$, melted in beryllia and thoria, respectively, were substantially free from carbide inclusions except for the extreme top where the carbide inclusions had concentrated, largely as a crust. Analysis of the crust showed a carbon content of 1,100 ppm. The section just below the crust contained $16 \mathrm{ppm}$ of carbon. A few carbide inclusions that were observed embedded in the side wall of ingots $A_{1}$ and $B$ probably account for the carbon contents of 5 and 7 ppm obtained on samples of these ingots.

Ingot $A_{2}$ had a similar concentration of carbide inclusions in the extreme top and the same freedom from carbide inclusions in the body of the ingot but differed from the other ingots in having a considerable concentration of very fine carbide inclusions in the side wall.

It is apparent that the elimination of carbon from the body of the ingot was the result of agglomeration and migration of the carbide inclusions to the top of the ingots during the periods that the metal was held quietly molten at temperatures just above the freezing point.

The analytical and metallographic data indicate that the increase in freezing temperature with increase in the time during which the metal was held molten was the result of increase in the purity of the metal. 


\section{Summary}

1. The data obtained in this investigation indicate that the freezing temperature of uranium of about 99.99 -percent purity is $1,133^{\circ} \pm 2^{\circ} \mathrm{C}$.

2 . The freezing temperature was not greatly affected by the crucible material, similar values for the freezing temperature being obtained in beryllia, thoria, and graphite crucibles.

3. Holding the metal at temperatures just above the melting point for several hours resulted in a decrease in the content of several impurities, by volatilization and by migration to the top and side walls. This increase in the purity of the metal was accompanied by an increase in the freezing temperature to a final constant value, $5^{\circ}$ or $6^{\circ} \mathrm{C}$ above the initial freezing temperature.

\section{References}

[1] International Critical Tables 1, 105 (1926); Van Nostrand's Chemical Annual, p. 294 (1926); Smith- sonian Physical Tables, p. 198 (1927); Kent's Mechanical Engineers Handbook, p. 596 (1933); General Engineering Handbook (O'Rourke), p. 126 (1940); Machinery's Handbook, p. 1579 (1943); Handbook of Chemistry and Physics, p. 1712 (1943).

[2] Brady's Materials Handbook, p. 502 (1940).

[3] Mark's Handbook (Mechanical Engineers), p. 546 (1924).

[4] NBS Misc. Pub. M126 (1937).

[5] Comprehensive Treatise on Inorganic and Theoretical Chemistry 12, 15 (Longmans Green \& Co., New York, N. Y., 1932).

[6] Ind. Eng. Chem. 22, 516 (1930).

[7] Z. anorg. chem. 81, 170 (1913).

[8] Unpublished work, Pyrometry Laboratory of the National Bureau of Standards.

[9] W. H. Swanger and F. R. Caldwell, BS J. Research 6, 1131 (1931) RP327.

[10] C. O. Fairchild and W. H. Hoover, J. Opt. Soc. Am. and Rev. Sci. Instr. \%, No. 7, p. 543 (1923).

[11] W. F. Roeser, F. R. Caldwell, and H. T. Wensel, BS J. Research 6, 1119 (1931) RP326.

Washington, August 11, 1949. 